\title{
The CASE survey: Patient and physician perceptions regarding asthma medication use and associated oropharyngeal symptoms
}

\author{
J Mark FitzGerald MB ChB FRCPC ${ }^{1}$, Charles KN Chan MD FRCPC FCCP FACP ${ }^{2}$, \\ Martin C Holroyde MSc PhD ${ }^{3}$, Louis-Philippe Boulet MD FRCPC ${ }^{4}$
}

\begin{abstract}
JM FitzGerald, CKN Chan, MC Holroyde, L-P Boulet. The CASE survey: Patient and physician perceptions regarding asthma medication use and associated oropharyngeal symptoms. Can Respir J 2008;15(1):27-32.
\end{abstract}

BACKGROUND: Oropharyngeal (OP) symptoms are common in asthma patients using inhaled corticosteroids (ICSs) alone and in combination with a long-acting beta ${ }_{2}$-agonist (LABA). Patterns of medication use, level of asthma control and association with OP symptoms are not often reported in a nonstudy setting.

OBJECTIVES: To determine the prevalence of OP symptoms among adult asthma patients using ICSs alone and an ICS plus a LABA; to investigate the relationships between medication use, asthma control and OP symptoms; and to assess family physicians' (FPs') perceptions of the prevalence and management of OP symptoms.

METHODS: A random telephone survey of 1003 asthma patients and 250 FPs treating asthma patients was conducted from February to March 2005 across Canada.

RESULTS: Twenty-four per cent of patients experienced OP symptoms; $67 \%$ of them spoke to their FPs about the OP symptoms. Thirty-one per cent of patients who experienced OP symptoms stopped or reduced their dose of medication. OP symptoms were reported by $25 \%$ of patients using ICSs and $22 \%$ using an ICS plus a LABA. The incidence of OP symptoms was not affected by the choice of inhalation device (metered-dose inhaler versus dry powder inhaler) or the use of a spacer. Fifty-eight per cent of patients had uncontrolled asthma; patients achieving a lower level of general education were more likely to have poor control. Patients with uncontrolled asthma were more likely than those with controlled asthma to report OP symptoms ( $28 \%$ versus $18 \%$, respectively; $\mathrm{P}<0.05$ ). Eightynine per cent of FPs had patients who had reported OP symptoms to them. FPs estimated that $15 \%$ of their patients experienced OP symptoms and that compliance to treatment worsened in approximately $20 \%$ of them.

CONCLUSIONS: The prevalence of OP symptoms in asthma patients using ICSs and an ICS plus a LABA is significant. OP symptoms were found to be associated with a reduced patient education level, with a likelihood of reducing or stopping medication, and with a less well-controlled asthma patient. While FPs recognized that a significant proportion of their asthma patients experience OP symptoms and that OP symptoms may affect compliance, they underestimated the prevalence of this problem.

Key Words: CASE survey; Inhaled corticosteroids; Oropharyngeal symptoms

\author{
L'enquête CASE : Perception des patients \\ et des médecins quant à l'utilisation des \\ antiasthmatiques et des symptômes oropharyngés \\ associés
}

HISTORIQUE : Les symptômes oropharyngés (OP) sont fréquents chez les patients asthmatiques qui utilisent des corticostéroïdes par inhalation (CSI), seuls ou en association avec un bêta ${ }_{2}$-agoniste à longue action (BALA). À l'extérieur des études cliniques, les rapports sur le mode d'utilisation des médicaments, le degré de maîtrise de l'asthme et leur relation avec les symptômes OP sont peu nombreux.

OBJECTIFS : Déterminer la prévalence des symptômes OP chez des patients asthmatiques adultes qui utilisent des CSI seuls ou un CSI plus un BALA. Analyser le lien entre l'utilisation des médicaments, la maîtrise de l'asthme et les symptômes OP et évaluer la perception des médecins de famille (MF) quant à la prévalence et la prise en charge des symptômes OP.

MÉTHODES : Une enquête téléphonique aléatoire auprès de 1003 patients asthmatiques et de $250 \mathrm{MF}$ traitant des patients asthmatiques a été réalisée entre février et mars 2005 un peu partout au Canada. RÉSULTATS : Vingt-quatre pour cent des patients éprouvaient des symptômes OP, 67 \% d'entre eux en avaient parlé à leur MF. Trente et un pour cent des patients qui manifestaient des symptômes OP ont cessé leur médicament ou en ont réduit la dose. Des symptômes OP ont été signalés par $25 \%$ des patients qui prenaient un CSI et par $22 \%$ des patients qui prenaient un CSI et un BALA. L'incidence des symptômes OP n'a pas été affectée par le choix de l'appareil d'inhalation (aérosol-doseur vs inhalateur de poudre sèche) ou par l'utilisation d'un espaceur. Cinquantehuit pour cent des patients présentaient un asthme non maittrisé. Les patients généralement moins scolarisés avaient davantage tendance à obtenir une moins bonne maîtrise de leur asthme. Les patients dont l'asthme n'était pas maîtrisé étaient plus susceptibles que les autres de signaler des symptômes OP $(28 \%$, contre $18 \%$, respectivement, $\mathrm{P}<0,05)$. Quatre-vingt-neuf pour cent des MF avaient des patients qui leur avaient signalé des symptômes OP. Les MF ont estimé que $15 \%$ de leurs patients présentaient des symptômes $\mathrm{OP}$ et que l'observance thérapeutique se détériorait chez environ $20 \%$ d'entre eux.

CONCLUSIONS : La prévalence des symptômes OP chez les patients asthmatiques qui utilisent des CSI ou un CSI plus un BALA est significative. Chez les patients, les symptômes OP se sont révélés associés à un degré de scolarité moindre, à une tendance à réduire la dose de médicament ou à cesser de le prendre et à un asthme moins bien maîtrisé. Si les MF ont reconnu qu'une proportion significative de leurs patients asthmatiques manifestent des symptômes OP et que ces derniers peuvent nuire à l'observance thérapeutique, ils semblent par contre sous-estimer la prévalence du problème.

${ }^{1}$ Centre for Clinical Epidemiology and Evaluation, University of British Columbia, Vancouver, British Columbia; ${ }^{2}$ University Health Network -

Toronto General Hospital, Toronto; ${ }^{3}$ Nycomed Canada Inc, Oakville, Ontario; ${ }^{4}$ Institut de cardiologie et de pneumologie de l'Université Laval, Hôpital Laval, Quebec City, Quebec

Correspondence and reprints: Dr J Mark FitzGerald, Centre for Clinical Epidemiology and Evaluation, Vancouver General Hospital Research Pavilion, 828 10th Avenue West, Vancouver, British Columbia V5Z 1L8. Telephone 604-875-4565, fax 604-875-5179,

e-mail markf@interchange.ubc.ca 
Inhaled corticosteroids (ICSs) reduce the airway inflammaItion characteristic of asthma and are the maintenance therapy of choice for most patients with persistent asthma (1-3). ICSs reduce asthma symptoms and the need for rescue medication. Their use is also associated with reductions in asthma exacerbations, emergency department visits and hospital admissions (4-6).

However, despite the availability of efficacious treatment, as well as the development of national and international asthma consensus guidelines (1-3), surveys of asthma management have repeatedly demonstrated that large numbers of asthma patients do not have well-controlled asthma $(7-10)$. The reasons for suboptimal management are many and varied. They include underdiagnosis of the disease, underestimation of its severity, inadequate treatment, insufficient patient education and lack of patient compliance (7-13).

It has long been recognized that the use of ICSs is associated with oropharyngeal (OP) symptoms such as hoarseness, dysphonia and oral candidiasis (14-17). These local side effects are often considered by clinicians to be relatively infrequent and minor problems. However, they have been shown to affect the comfort and lifestyle of patients, and may have a negative impact on compliance with treatment (14-17).

In conducting the present Control of Asthma and Side Effects (CASE) survey, we set out to investigate the relationships between OP symptoms, use of inhaled medications containing corticosteroids and asthma control in a nonstudy setting by means of random national telephone surveys of asthma patients and primary care physicians who reported treating asthma patients.

\section{PATIENTS AND METHODS}

Random telephone surveys were conducted across Canada with 1003 asthma patients and 250 family physicians (FPs) or general practitioners in February to March 2005.

\section{Patients}

Patient names were sampled from a consumer database managed by ICOM Information \& Communications Inc (Toronto, Ontario). Seventy-two per cent of 20,000 attempted contacts with asthma patients were unsuccessful (no answer, line busy, respondent refused to participate, etc). A total of 5634 respondents underwent eligibility screening, and 1003 interviews were completed. Eligibility criteria included diagnosis of asthma confirmed by a physician; age of 18 years or older; and current treatment with an ICS alone or in combination therapy with a long-acting beta 2 -agonist (LABA), or alternatively, recent treatment stopped within the previous 12 months.

Geographic distribution and sex of patients were controlled by quotas, ie, the number and sex of patients interviewed in regions across Canada were matched to the number of asthma patients in those regions, as reported by Statistics Canada. Age range distribution was weighted as per age ranges reported by Statistics Canada.

During the telephone interview, a questionnaire was administered to derive the following information:

- level of asthma control achieved;

- asthma medications used (including formulation and device);

- experience of OP symptoms while taking the asthma medications;
- actions recommended by the patient's physician to manage OP symptoms and actions taken by the patient; and

- basic patient demographics, including the highest level of general education achieved.

Asthma control among patients was assessed using the 30 Second Asthma Test (GlaxoSmithKline, Canada) (18), which uses five of the six symptom-based control criteria outlined in the Canadian asthma consensus guidelines (1). Patients' asthma was considered uncontrolled if they answered 'yes' to two or more of the questions contained in the 30 Second Asthma Test.

With regard to OP symptoms, patients were asked, "Have you ever experienced any sore throat, hoarseness and/or mouth sores while taking XX?", where XX represented Advair (GlaxoSmithKline, Canada), Flovent (GlaxoSmithKline, Canada), Pulmicort (AstraZeneca Inc, Canada), QVAR (Graceway Pharmaceuticals, USA) or Symbicort (AstraZeneca Inc, Canada) (in this case, the interviewer inserted the appropriate medication, which the patient had previously revealed he or she was taking).

\section{Physicians}

The names of FPs were sampled at random from a database of over 18,000 physician names previously identified as being prescribers of inhaled steroids and combination therapy. Eligibility criteria were treating asthma patients 18 years of age or older, and writing at least 25 prescriptions per week for ICSs and at least three prescriptions per week for an ICS plus a LABA. A total of 274 FPs were screened; 24 of those interviews were terminated because the FPs did not meet the ICS or ICS plus LABA prescription writing requirements. Provincial quotas were controlled to reflect population proportions across Canada.

During the telephone interview, a questionnaire was administered to derive the following information:

- demographics, including practice size;

- asthma medications prescribed, including dose and device;

- proportion of controlled patients;

- proportion of patients who had experienced OP symptoms, and proportion who had reported OP symptoms;

- OP symptom management strategies recommended; and

- impact of OP symptoms on patient compliance.

A target sample size of 1000 patients and 250 physicians was chosen to match that achieved in an earlier survey of asthma in Canada (7), so as to reach a similar level of statistical significance and facilitate comparisons between the two studies.

Differences between observed frequencies and/or means were tested for statistical significance at the $95 \%$ confidence level using the $z$ test. The $95 \%$ confidence limits were $\pm 1.4 \%$ (patient sample) and $\pm 2.7 \%$ (physician sample).

\section{Patient-reported data}

\section{RESULTS}

Of the 1003 patients interviewed, 943 were currently using an ICS or an ICS plus a LABA; 60 patients had used an ICS or an 
ICS plus a LABA in the past but had stopped within the previous 12 months. Data for these two groups were analyzed separately. Results proved to be consistent between the two groups and are reported here as one data set.

Patient demographics: Sixty per cent of the patients were women. There were no significant regional differences (Atlantic, Quebec, Ontario, Prairies, British Columbia) in the highest level of general education attained by patients. Results for the overall population were $5 \%$ primary school, $41 \%$ high school, 28\% college/Collège d'enseignement général et professionnel ("College of General and Vocational Education"), 22\% university and 3\% postgraduate education. The 25 - to 34-year-old age group was the most educated group, with $68 \%$ attaining postsecondary education. Fifty-seven per cent of patients were employed (45\% full-time and 12\% part-time), 39\% were unemployed or retired, and $4 \%$ were students. Patients had had a history of asthma for a mean of 17.5 years. There was no difference in the length of time having had asthma between sexes, or between those with controlled (17.4 years) and uncontrolled (17.8 years) asthma.

Medications used: Overall, 63\% of patients were using ICS monotherapy $(47 \%$ fluticasone, $15 \%$ budesonide, $1 \%$ beclomethasone) and 37\% were using an ICS plus a LABA (24\% fluticasone plus salmeterol, 13\% budesonide plus formoterol). These data are in accordance with the market share of these products in Canada. Similarly, the relative proportions of metered-dose inhalers (MDIs) and dry powder inhalers (DPIs) were as expected from the relative market share of these products (fluticasone: $86 \%$ MDI and 14\% DPI; budesonide: $100 \%$ DPI; beclomethasone: $100 \%$ MDI; fluticasone plus salmeterol: 35\% MDI and 65\% DPI; budesonide plus formoterol: $100 \%$ DPI). Of the 515 patients who used medication in the MDI format, $46 \%$ reported using a spacer or holding chamber.

Asthma control: Fifty-eight per cent of asthma patients had uncontrolled asthma, based on the 30 Second Asthma Test (18). Less well-educated patients were more likely to have poor control: $64 \%$ of those whose highest attained level of education was primary or high school had uncontrolled asthma. Significantly fewer patients who had attained university or postgraduate education $(51 \% ; \mathrm{P}<0.05)$ had uncontrolled asthma.

Regional differences in asthma control were observed, with Atlantic Canada having a significantly higher proportion of uncontrolled asthma patients (74\%) than Ontario (55\%), the Prairies (54\%) or British Columbia (54\%). Quebec (61\%) was not significantly different from the other regions.

Comparing users of fluticasone $(n=471)$ with those using fluticasone plus salmeterol $(n=243)$, there was no significant difference in the proportion of controlled asthma patients (42\% versus $37 \%$, respectively). Similar results were seen when comparing all patients taking ICS monotherapy $(n=631)$ with all patients taking an ICS plus a LABA ( $n=369)$ : $44 \%$ versus $40 \%$ controlled, respectively (Figure 1 ).

OP symptoms: Overall, $24 \%$ of patients reported having experienced sore throat, hoarseness and/or mouth sores while using ICS or ICS plus LABA medications. The incidence of OP symptoms was 25\% with an ICS (30\% budesonide, 29\% beclomethasone, $23 \%$ fluticasone) and $22 \%$ with an ICS plus a LABA (24\% fluticasone plus salmeterol, 19\% budesonide plus formoterol); there were no statistically significant differences between any of these products. The incidence of OP symptoms was not significantly affected by the use of a spacer

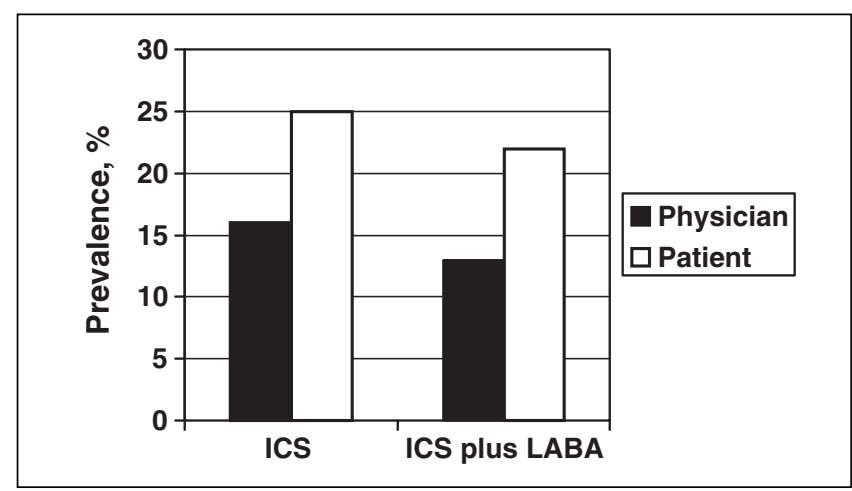

Figure 1) Prevalence of oropharyngeal symptoms associated with the use of an inhaled corticosteroid (ICS) alone or in combination with a long-acting beta $a_{2}$-agonist (LABA) in asthma patients, as reported by patients $(n=1003)$ and physicians $(n=250)$

or by the choice of delivery device (MDI or DPI) (data not shown). Patients with uncontrolled asthma were more likely to report OP symptoms than those with controlled asthma (28\% versus $18 \%$; $\mathrm{P}<0.05)$. Among all the patients who experienced OP symptoms, lack of asthma control was more likely to be associated with lower education; $51 \%$ of the uncontrolled group versus $30 \%$ of the controlled group $(\mathrm{P}<0.05)$ stated that their highest level of education attained was primary or high school.

Therapy interventions: Sixty-seven per cent of patients who experienced OP symptoms spoke with their FP about the side effects. There were no significant differences among the patients who spoke with their FPs in terms of medication or formulation, demographics, or whether their asthma was controlled versus uncontrolled. The physicians told $81 \%$ of patients to rinse their mouths, use mouthwash or gargle; $23 \%$ were told to wait and see, or to continue taking the medication as prescribed. Twenty-three per cent of patients were advised to either reduce their dose or stop taking their medication for a while before restarting. Of those patients who did not consult their physician about OP symptoms, 25\% either reduced their dose or stopped taking their medication. Overall, $31 \%$ of patients who experienced OP symptoms (regardless of whether they spoke to their physicians about the side effects) either reduced their dose or stopped taking their medication.

\section{Physician-reported data}

Physician demographics: The FP study participants were experienced physicians (qualified for at least 20 years), and the majority (52\%) were 'early adopters' of new asthma therapies. Thirty-six per cent were affiliated with teaching hospitals and $45 \%$ with nonteaching hospitals. The mean number of asthma patients per practice was 323, with 166 (51\%) using an ICS (62\% fluticasone, $31 \%$ budesonide, $7 \%$ beclomethasone) and 125 (39\%) using an ICS plus a LABA (60\% fluticasone plus salmeterol, 40\% budesonide plus formoterol).

Asthma control: Overall, the FPs estimated that $62 \%$ of their patients were 'totally under control'. However, they also believed that significantly more patients taking an ICS plus a LABA were controlled than those taking an ICS alone $(74 \%$ versus $61 \%$, respectively).

OP symptoms: Eighty-nine per cent of FPs had patients who had reported OP symptoms to them. Overall, they believed 


\begin{tabular}{lcc}
$\begin{array}{l}\text { TABLE 1 } \\
\text { Management of oropharyngeal side effects: Physician } \\
\text { recommendations, as reported by }\end{array}$ & $\begin{array}{c}\text { Reported by } \\
\text { patient, \% } \\
\text { (n=153) }\end{array}$ & $\begin{array}{c}\text { Reported by } \\
\text { physician, \% } \\
\text { (n=222) }\end{array}$ \\
\hline & 80 & 89 \\
\hline Rinse mouth, use mouthwash or gargle & 23 & $7^{*}$ \\
Wait and see, or continue taking as prescribed & 6 & 6 \\
Stop therapy and restart after a while & 0 & $8^{*}$ \\
Switch to another therapy & 16 & $5^{*}$ \\
Reduce frequency of puffs per day & 11 & $4^{*}$ \\
Maintain frequency but reduce number of puffs & & \\
per dose & 0 & $4^{*}$ \\
Use a spacer or chamber & 0 & $8^{*}$ \\
Add antifungal treatment (eg, nystatin) &
\end{tabular}

Numbers indicate the percentage of patients who were advised to carry out the action (patient response), or percentage of patients to whom a physician would provide the advice (physician response); multiple responses were permitted. *Significantly different from patient response at $P<0.05$ (by z test)

that $15 \%$ of their patients had experienced OP symptoms and that $14 \%$ had reported them. Interestingly, physicians in Quebec perceived that a significantly higher proportion of their patients have complained about OP symptoms than those in Ontario ( $13 \%$ versus $8 \%$ of patients, respectively). Physicians reported that all currently available formulations of ICSs or ICSs plus LABAs had been associated with patient complaints of OP symptoms; there were no perceived differences between the products. Overall, the FPs estimated that compliance to treatment worsened in $22 \%$ of patients who had experienced $\mathrm{OP}$ symptoms.

Therapy interventions: The main course of action suggested by FPs to patients reporting OP symptoms was to rinse their mouths, use mouthwash or gargle (for $89 \%$ of patients). Other options, such as switching or stopping therapy, or prescribing an antifungal agent or spacer, were suggested for less than $10 \%$ of patients. Physician and patient responses regarding the management of OP symptoms are compared in Table 1.

Overall, FPs estimated that only $15 \%$ of their patients were advised to undergo therapy interventions (dose adjustment, or stopping and starting therapy).

\section{DISCUSSION}

The present survey confirms the results of two previous surveys regarding the level of asthma control in Canada $(7,8)$, producing very similar data. All three suggest that the proportion of asthma patients who remained uncontrolled did not change over the previous seven years (57\% in 1999, 53\% in 2004 and $58 \%$ in 2005). The surveys also highlight the different perceptions of patients and physicians regarding asthma control, and the apparent suboptimal level of communication between them. For example, in the present survey, physicians estimated that $62 \%$ of their patients were 'totally under control', whereas only $42 \%$ of the patients surveyed could have been considered controlled based on the 30 Second Asthma Test.

It is also interesting that physicians believed that significantly more patients taking an ICS plus a LABA were controlled than those taking an ICS alone (74\% of patients versus $61 \%$, respectively). In contrast, the patient survey revealed no difference in the level of control achieved by these two classes of drug. This observation should be interpreted with caution, because no data are available to ascertain, for example, whether the patients prescribed an ICS plus a LABA had more severe asthma. Nevertheless, this observation may indicate that in the real world (outside the rigid confines of a clinical trial), the expected greater effectiveness of the combination product is not necessarily apparent. One may speculate that this is a reflection of poor patient compliance, impacting the effectiveness of ICSs and ICSs plus LABAs equally. Indeed, a recent study of adherence and persistence among 5504 patients who were prescribed the salmeterol-fluticasone combination in the United States revealed that the adherence rate was only $8.8 \%$ over one year (11).

There are many possible reasons for the failure to achieve asthma control, and they have been reviewed elsewhere (7-9). However, it is widely believed that patient nonadherence to therapy is one of the main factors involved. According to Bender and Bender (19), the most common reason cited by patients for poor adherence is the fear of adverse effects. Similar observations arose in a survey of 603 Canadian asthma patients carried out in 1995, in which $59 \%$ admitted to a fear of side effects associated with the use of ICSs (20). In a more recent survey of 893 patients, $75 \%$ expressed concerns about taking an ICS, and $81 \%$ expressed a desire to use less over the long term (8). Clearly, patient fears of ICS-induced adverse effects remain a barrier to adherence and therefore the achievement of optimal asthma control.

Estimates of local adverse effects associated with ICS therapy vary widely. Reviews of the literature include reports of dysphonia affecting $5 \%$ to $58 \%$ of patients, candidiasis affecting $0 \%$ to $70 \%$ and pharyngitis affecting $4 \%$ to $25 \%(14,15)$.

Few studies have systematically investigated the local side effects of ICSs. In a survey of 269 asthma patients attending a hospital outpatient clinic and using an ICS MDI, Williamson et al (16) reported that $58 \%$ of the patients reported throat symptoms or dysphonia, compared with $13 \%$ of control subjects (comprising attendees at a diabetic outpatient clinic). Throat symptoms were more prevalent in patients using higher doses of ICSs. Local side effects were equally prevalent with beclomethasone and budesonide inhalers, and were not modified by the use of a large volume spacer.

In the present study, 24\% of Canadian asthma patients reported that they had experienced OP symptoms, such as sore throat, hoarseness and/or mouth sores, while using an ICS or an ICS plus a LABA. There was no significant difference between product classes. OP symptoms were associated with patients having a lower education level and less wellcontrolled asthma.

The patient survey indicated that $24 \%$ of patients had experienced OP symptoms, but only $16 \%$ had reported them. The under-reporting of OP symptoms thus seems to be the result of patients choosing not to discuss their OP symptoms with their physicians.

Sixty-seven per cent of patients who had spoken with their FPs about their OP symptoms reported that they had been most frequently advised to rinse their mouths, use a mouthwash or gargle. Twenty-three per cent reported that they had undergone therapy intervention (dose adjustment, or stopping and starting therapy).

The FPs also reported that they most commonly had advised patients to rinse, use a mouthwash or gargle. In other respects, however, the FPs view of the actions they were likely recommended was very different from the advice that 
patients recollected having received from their physicians (Table 1). This may represent another example of a communication gap between patients and physicians, but it may also suggest that physicians do not wish to admit to an interviewer that they may condone certain actions such as 'wait and see' (ie, ignore the symptoms for a while) or reduce the daily dose of the medication (with the risk that this may lead to poorer asthma control).

In general, the actions recommended by the FPs in the present survey to manage OP symptoms are logical, although in some situations, they may not be successful. Rinsing or gargling is intended to remove ICSs deposited in the oropharynx. This may reduce the incidence of candidiasis, but it is unlikely to impact dysphonia $(16,21)$. It is not clear whether switching medications can improve matters. All of the ICSs available in Canada at the time the present survey was conducted have been associated with OP side effects, although one recent meta-analysis suggested a significantly higher probability of developing pharyngitis with fluticasone than with beclomethasone or budesonide (22). Reducing the frequency of ICS administration may be effective: Toogood et al (23) showed that twice-daily dosing with budesonide significantly reduced the incidence of candidiasis compared with four times daily dosing. Finally, spacers are often used because they have been shown to reduce the OP deposition of the aerosol delivered by an MDI and may therefore be expected to reduce the incidence of OP symptoms (14). However, it should be noted that their usefulness in limiting OP symptoms may be variable: one study showed some benefit (24), one showed no difference (16) and one associated the use of a spacer with a doubling of the incidence of cough in children (17). In the present study, the use of a spacer had no significant effect on the incidence of OP symptoms in patients using MDI formulations.

Approximately one-third (31\%) of all patients who had experienced OP symptoms (regardless of whether they spoke to their FPs about them) underwent therapy interventions. Twenty-four per cent reduced the total daily dose (took their therapy less frequently during the day while maintaining the same number of puffs taken each time [18\%] and/or reduced the total number of puffs per day while maintaining the daily dose frequency [14\%]). Twelve per cent stopped therapy for a while and then restarted. These findings are strikingly similar to those of the recently completed Global Asthma Physician and Patient (GAPP) survey (25).

\section{REFERENCES}

1. Boulet LP, Becker A, Bérubé D, Beveridge R, Ernst P. Canadian asthma consensus report, 1999. CMAJ 1999;161(11 Suppl):S1-S62.

2. Lemière $\mathrm{C}$, Bai $\mathrm{T}$, Balter $\mathrm{M}$, et al. Adult asthma consensus guidelines update 2003. Can Respir J 2004;11(Suppl A):9A-18A.

3. Global Initiative for Asthma: Global Strategy for Asthma Management and Prevention. NHLBI/WHO workshop report. <www.ginasthma.com> (Version current at November 22, 2006).

4. Barnes PJ. Inhaled glucocorticoids for asthma. N Engl J Med 1995;332:868-75.

5. Barnes PJ, Pedersen S, Busse WW. Efficacy and safety of inhaled corticosteroids. New developments. Am J Respir Crit Care Med 1998;157:S1-53.

6. Suissa S, Ernst P, Kezouh A. Regular use of inhaled corticosteroids and the long term prevention of hospitalisation for asthma. Thorax 2002;57:880-4.

7. Chapman KR, Ernst P, Grenville A, Dewland P, Zimmerman S. Control of asthma in Canada: Failure to achieve guideline targets. Can Respir J 2001;8(Suppl A):35A-40A.
The nonadherence to therapy by patients in the present survey (whether on their own initiative or on the advice of their FPs) likely had a significant impact on asthma control. It is noteworthy that patients with OP symptoms were less likely to have well-controlled asthma.

The present survey had some limitations. With all telephone surveys, the data are self-reported, and are therefore subject to limitations of recall and perhaps the personal perceptions of the patients and physicians. Assessment of asthma control did not include any objective measures but, rather, was based on patient responses to a series of questions based on the Canadian consensus guidelines. However, in this respect, the survey was identical to two previous major surveys of asthma control in Canada $(7,8)$. Although the questionnaire administered in the present survey was designed to explore the occurrence of OP symptoms associated with the use of ICSs or ICSs plus LABAs, we cannot absolutely exclude the possibility that in a few patients, the OP symptoms were related to postnasal drip following rhinitis or a common cold. A link between upper airway conditions and dysphonia or throat irritation is theoretically possible, although we were unable to find any studies of this in the literature. Further research on this topic is needed. Finally, no attempt was made to differentiate among candidiasis, dysphonia and pharyngitis, and objective data to confirm these diagnoses (eg, cultures for candidiasis) were not available.

\section{CONCLUSIONS}

In the present study, we found a significant prevalence of OP symptoms in asthma patients using ICSs and ICSs plus LABAs. These symptoms were associated with poorer control of asthma, which in turn was associated with a reduced patient education level. OP symptoms were also associated with an increased likelihood of reducing or stopping medication, which likely led to less well-controlled asthma. While FPs recognized that a significant proportion of their asthma patients experience OP symptoms and that OP symptoms may affect compliance, they underestimated the magnitude of this problem.

ACKNOWLEDGEMENTS: J Mark FitzGerald is a Michael Smith Distinguished Scholar Award and a recipient of a Canadian Institutes of Health Research/British Columbia Lung Scientist Award.

FUNDING: This survey was funded by ALTANA Pharma Inc.
8. FitzGerald JM, Boulet LP, McIvor RA, Zimmerman S, Chapman KR. Asthma control in Canada remains suboptimal: The Reality of Asthma Control (TRAC) study. Can Respir J 2006;13:253-9.

9. Kips JC, Pauwels RA. Asthma control: Where do we fail? Eur Respir J 2000;16:797-8.

10. Boulet LP, Phillips R, O'Byrne P, Becker A. Evaluation of asthma control by physicians and patients: Comparison with current guidelines. Can Respir J 2002;9:417-23.

11. Bender BG, Pedan A, Varasteh LT. Adherence and persistence with fluticasone propionate/salmeterol combination therapy. J Allergy Clin Immunol 2006;118:899-904.

12. Côté J, Cartier A, Robichaud P, et al. Influence of asthma education on asthma severity, quality of life and environmental control. Can Respir J 2000;7:395-400.

13. Côté J, Cartier A, Malo JL, Rouleau M, Boulet LP. Compliance with peak expiratory flow monitoring in home management of asthma. Chest 1998;113:968-72. 
14. Roland NJ, Bhalla RK, Earis J. The local side effects of inhaled corticosteroids: Current understanding and review of the literature. Chest 2004;126:213-9.

15. Buhl R. Local oropharyngeal side effects of inhaled corticosteroids in patients with asthma. Allergy 2006;61:518-26.

16. Williamson IJ, Matusiewicz SP, Brown PH, Greening AP, Crompton GK. Frequency of voice problems and cough in patients using pressurized aerosol inhaled steroid preparations. Eur Respir J 1995;8:590-2.

17. Dubus JC, Marguet C, Deschildre A, et al. Local side-effects of inhaled corticosteroids in asthmatic children: Influence of drug, dose, age, and device. Allergy 2001;56:944-8.

18. The 30 Second Asthma Test. <www.asthmaguidelines.com/down loads/30_Second_Test.pdf > (Version current at December 17, 2006).

19. Bender BG, Bender SE. Patient-identified barriers to asthma treatment adherence: Responses to interviews, focus groups, and questionnaires. Immunol Allergy Clin North Am 2005;25:107-30.
20. Boulet LP. Perception of the role and potential side effects of inhaled corticosteroids among asthmatic patients. Chest 1998;113:587-92.

21. Toogood JH, Jennings B, Greenway RW, Chuang L. Candidiasis and dysphonia complicating beclomethasone treatment of asthma. J Allergy Clin Immunol 1980;65:145-53.

22. Adams N, Bestall JM, Lasserson TJ, Jones PW. Inhaled fluticasone versus inhaled beclomethasone or inhaled budesonide for chronic asthma. Cochrane Database Syst Rev 2004:CD002310.

23. Toogood JH, Jennings B, Baskerville J, Anderson J, Johansson SA. Dosing regimen of budesonide and occurrence of oropharyngeal complications. Eur J Respir Dis 1984;65:35-44.

24. Selroos O, Backman R, Forsén KO, et al. Local side-effects during 4-year treatment with inhaled corticosteroids: A comparison between pressurized metered-dose inhalers and Turbuhaler. Allergy 1994;49:888-90.

25. The Global Asthma Physician and Patient Survey. $<$ www.gappsurvey.org> (Version current at November 22, 2007). 


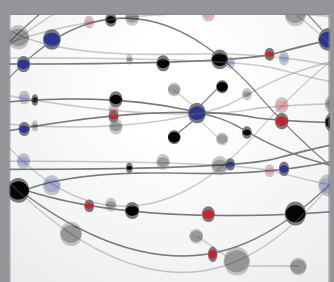

The Scientific World Journal
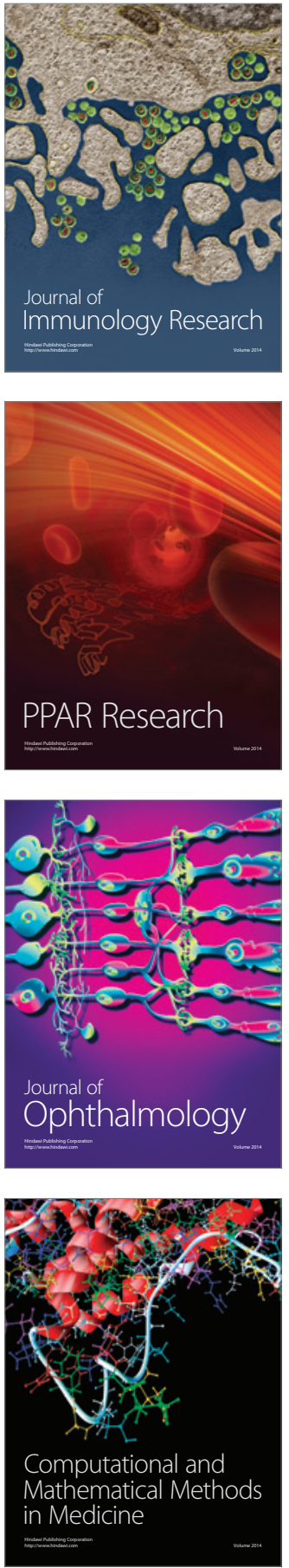

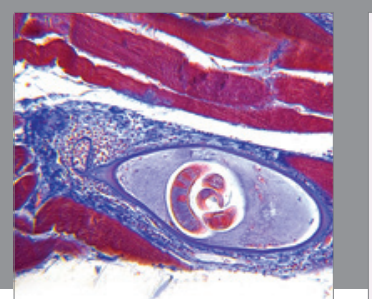

Gastroenterology Research and Practice

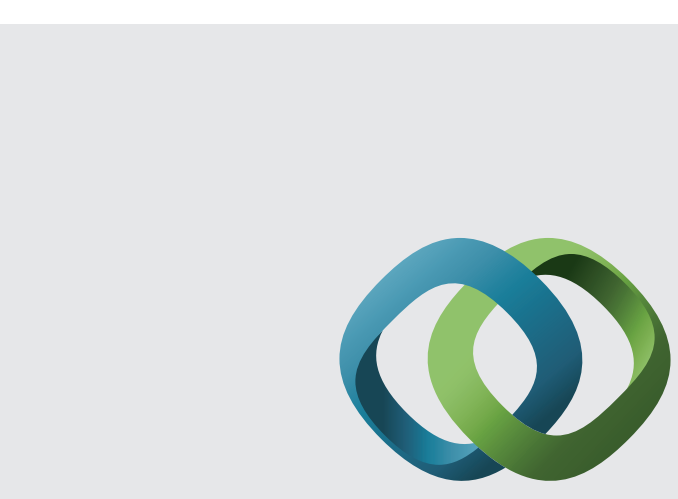

\section{Hindawi}

Submit your manuscripts at

http://www.hindawi.com
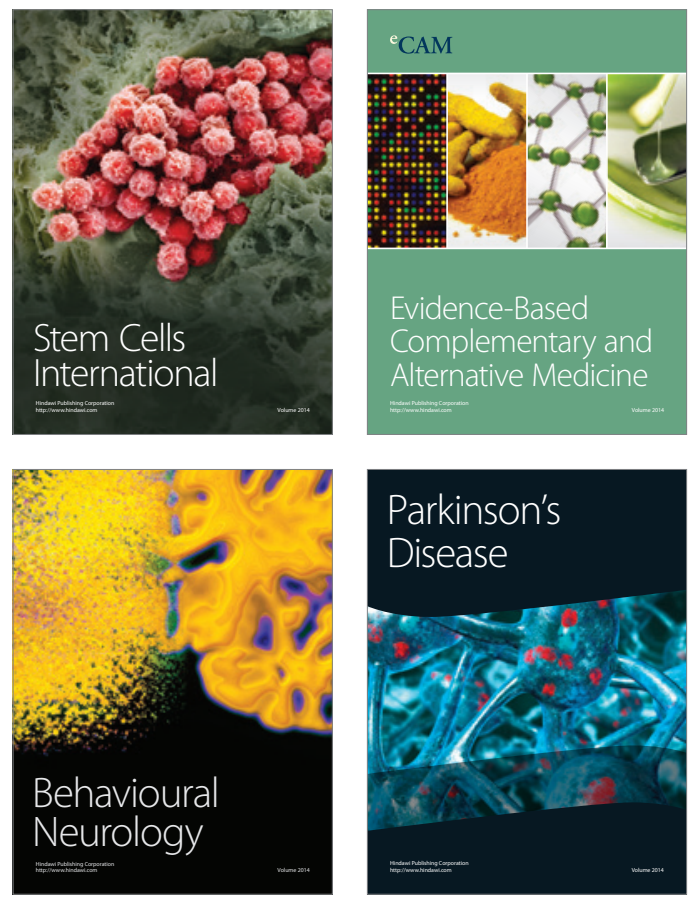
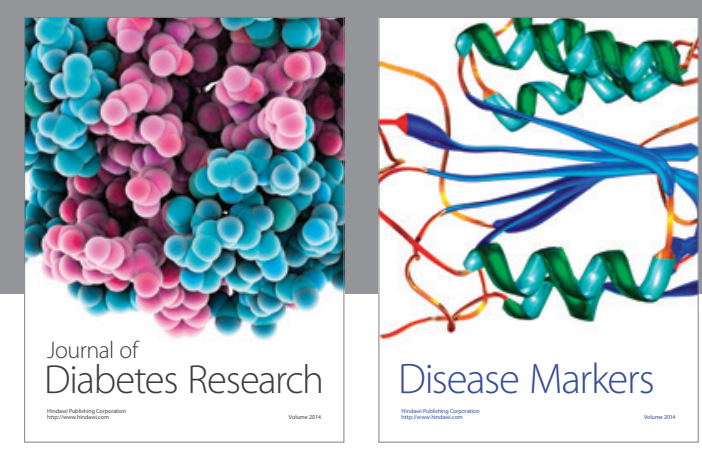

Disease Markers
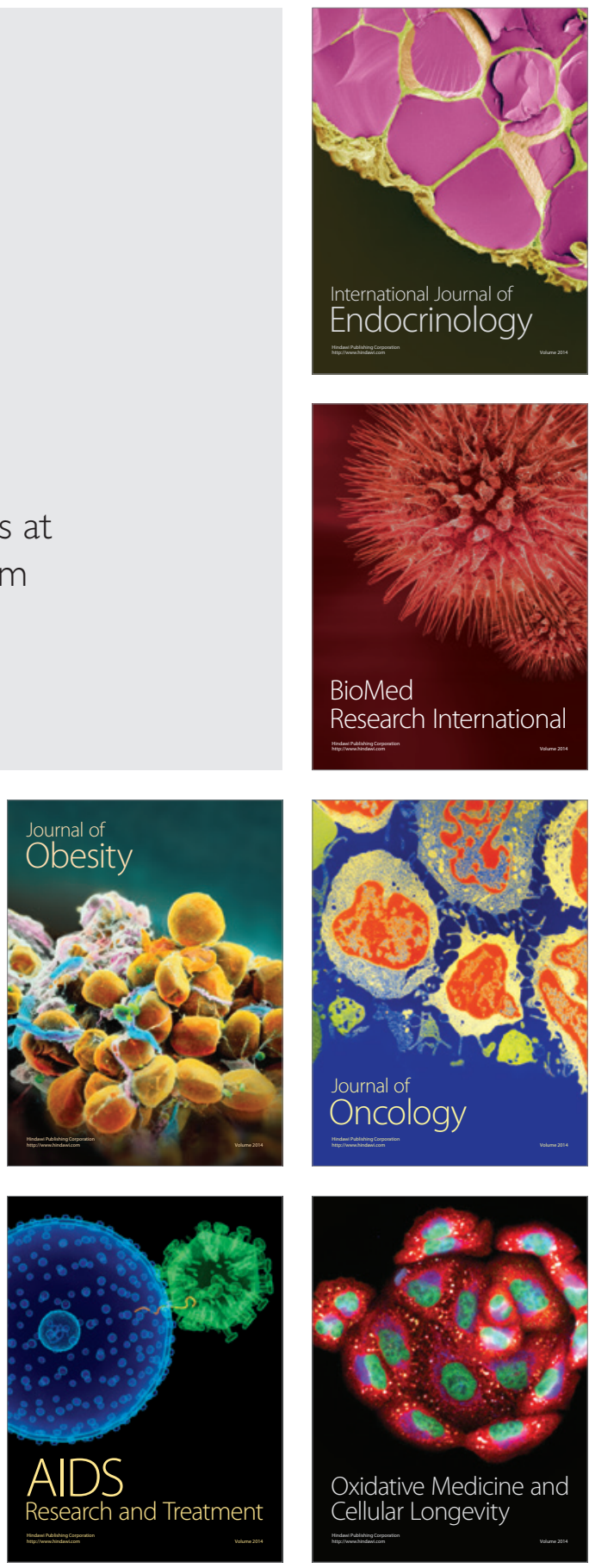